\title{
NGHIÊN CỨU SƯ DỤNG DŨ' LIẸU ẢNH MÁY BAY KHÔNG NGƯỜI LÁI (UAV) TRONG THÀNH LẬP BẢN ĐỒ ĐỊA HİNH TỶ LỆ LỚN
}

\author{
MAI VĂN SY̛('(1), BÙl NGỌC QUÝ(2), PHẠM VĂN HIẸP(2), LÊ ĐìNH QUÝ(2) \\ ${ }^{(1)}$ Công ty cổ phần tư vấn thiết kế công trình xây dựng Hải Phòng \\ ${ }^{(2)}$ Trường Đại học Mỏ - Địa chất
}

\section{Tóm tắt:}

Công nghệ chụp ảnh từ các thiết bị bay không người lái đã và đang được quan tâm nghiên cứu trong nhiều lĩnh vực trong đó có công tác thành lập bản đồ địa hình. Bài báo giới thiệu kết quả nghiên cứu sử dụng dữ liệu ảnh chụp từ thiết bị bay không người lái (UAV) trong công tác thành lập mảnh bản đồ địa hình F-48-80-(9-f-III) tỷ lệ 1:1000 khu vực xã Tân Triều, huyện Thanh Trì, thành phố Hà Nội.

\section{1. Đặt vấn đề}

Ngày nay, công nghệ viễn thám trên thế giới phát triển khá đa dạng, có rất nhiều thiết bị thu nhận các hình ảnh có độ phân giải mặt đất từ vài centimet đến hàng chục mét, có thể chụp ở cự ly rất gần vài chục mét cho đến khoảng cách rất xa hàng trăm kilomet như: chụp ảnh vệ tinh, chụp ảnh hàng không bằng máy bay có người lái và không người lái (UAV), công nghệ quét Lidar.

Công tác thành lập bản đồ địa hình tỷ lệ lớn 1:2000, 1:1000,...thường chỉ được thành lập cho các khu vực có diện tích không lớn phục vụ các mục đích thiết kế và triển khai các thiết kế cho những công trình do vậy thường được sử dụng phương pháp đo đạc trực tiếp. Tuy nhiên, phương pháp này mất khá nhiều thời gian và công sức. Trong khi đó, tư liệu ảnh chụp từ thiết bị bay không người lái bằng máy chụp ảnh phổ thông với độ cao bay chụp thấp, khả năng linh hoạt trong triển khai ngoài thực địa là một hướng nghiên cứu có ý nghĩa khoa học và thực tiễn.

Nội dung bài báo này sẽ tập trung vào nghiên cứu và sử dụng thiết bị bay không người lái (UAV) trong công tác thành lập bản đồ địa hình 1:1.000.

2. Tổng quan về máy bay không người lái phục vụ thành lập bản đồ

\subsection{Khái niệm về UAV}

UAV là viết tắt của "Unmanned Aerial Vehicle", nó có nghĩa là "phương tiện hàng không không người lái" hay thường gọi là "máy bay không người lái". Người ta có thể điều khiển chúng thông qua sóng radio (đối với các loại UAV tầm gần) hoặc thông qua các vệ tinh trung gian (đối với các loại UAV tầm xa).

\subsection{Phân loại UAV}

Trong thực tế có nhiều loại UAV và cách phân loại chúng. Tuy nhiên, những loại được sử dụng trong ngành Trắc địa - Bản đồ thì chúng ta có thể chia thành hai loại: dùng bệ phóng và lên thẳng. (Xem bảng 1)

2.3. Các thành phần của hệ thống máy bay không người lái (UAV)

2.3.1. Vật mang (máy bay)

Vật mang của hệ thống là máy bay được

Ngày nhận bài: 30/8/2017, ngày chuyển phản biện: 05/9/2017, ngày chấp nhận phản biện: 14/9/2017, ngày chấp nhận đăng: 19/9/2017 
thiết kế để gắn các hệ thống máy ảnh/hoặc camera số, thiết bị định vị và dẫn đường như GPS, IMU. Có nhiều loại như: loại cất cánh có bệ phóng; loại lên thẳng có nhiều cánh quạt, như hệ thống VUX-1UAV của hãng RIEGL với 8 cánh quạt 2 tầng có thể mang thiết bị đến $3,6 \mathrm{~kg}$.

Nhờ có hệ thống định vị quán tính IMU các hệ thống hiện đại có thể giảm được tác động của gió, được cân bằng tự động và đồng bộ tâm máy ảnh, GPS.

\subsubsection{Thiết bị dẫn đường GPS}

Hệ thống định vị toàn cầu GPS là hệ thống xác định vị trí bằng cách đo khoảng cách tới các vệ tinh, nó không chỉ tạo ra khả năng mới cho việc dẫn đường bay, mà còn cho cả việc xác định tọa độ không gian (X,Y,h) của tâm chụp.

Sau khi GPS được ứng dụng vào chụp ảnh hàng không, ta tính được tọa độ, độ cao tâm ảnh vào thời điểm chụp ảnh, các thông số này là yếu tố hỗ trợ thêm trong phần mềm tăng dày tọa độ điểm khống chế ảnh nội nghiệp, nhưng chỉ có một mình số liệu GPS thì chưa tính được các nguyên tố định hướng ảnh. Muốn xác định được nguyên tố định hướng ảnh tại thời điểm chụp ảnh, thì ta phải đưa vào hệ thống thiết bị định vị quán tính (IMU).
Khi kết hợp GPS và IMU vào chụp ảnh hàng không thì ta có thể tính toán được tọa độ tâm ảnh và nguyên tố định hướng ngoài của tấm ảnh tại thời điểm chụp ảnh.

\subsubsection{Máy chụp ảnh}

Đặc trưng chủ yếu của các máy ảnh kỹ thuật số là có sai số méo hình kính vật nhỏ, độ ổn định cao và được thiết kế đồng bộ với các hệ thống GPS/IMU cùng với các phần mềm xử lý số liệu tâm chụp một cách chuyên dụng. Hiện nay, trên thế giới cũng như ở Việt Nam dùng các loại máy ảnh phải đáp ứng được những tính năng cơ bản sau:

- Quang sai máy chụp ảnh phải nhỏ;

- Độ phân giải ống kính phải cao và độ nét của ảnh phải được đảm bảo trong toàn bộ trường ảnh;

- Các yếu tố định hướng trong phải được xác định chính xác, (ví dụ: chiều dài tiêu cự, toạ độ điểm chính ảnh...); Trục quang của ống kính phải vuông góc với mặt phẳng phim;

- Hệ thống chống nhòe phải đủ khả năng loại trừ ảnh hưởng của chuyển động tương đối giữa vật mang và Trái Đất.

\section{Thành lập bản đồ địa hình tỷ lệ lớn từ dữ liệu ảnh UAV}

Bảng 1: So sánh giữa hai loại UAV

\begin{tabular}{|c|c|c|}
\hline & Dùng bệ phóng & Lên thẳng \\
\hline Công việc & Thành lập bản đồ khu vực rộng & $\begin{array}{c}\text { Thành lập bản đồ khu vực nhỏ; } \\
\text { kiểm tra }\end{array}$ \\
\hline Ứng dụng & $\begin{array}{c}\text { Khảo sát, nông nghiệp, GIS, } \\
\text { môi trường, xây dựng... }\end{array}$ & $\begin{array}{c}\text { Quay phim, chụp ảnh, khảo sát, } \\
\text { xây dựng... }\end{array}$ \\
\hline Độ phân giải mặt đất (GSD) & Có thể đạt $1,5 \mathrm{~cm} /$ pixel & Có thể đạt $0,1 \mathrm{~cm} /$ pixel \\
\hline Tốc độ bay & Cao $40 \div 90 \mathrm{~km} / \mathrm{h}$ & Thấp $14 \div 60 \mathrm{~km} / \mathrm{h}$ \\
\hline Thời gian bay & Dài $70 \div 90$ phút & Ngắn $15 \div 30$ phút \\
\hline Diện tích bay chụp & Rộng & Nhỏ \\
\hline Cách thức cất cánh/hạ cánh thẳng & Dùng bệ phóng/Bung dù & Nhỏ \\
\hline Khu vực cất/hạ cánh & Rộng & \\
\hline
\end{tabular}


3.1. Quy trình công nghệ thành lập bản đồ địa hình từ dưr liệu ảnh UAV(hình 1)

\subsection{Công tác chuẩn bị}

- Tiến hành khái quát địa lý khu vực cần thành lập bản đồ, từ đó ta có tiêu chí để lựa chọn các đối tượng, hiện tượng để thể hiện lên bản đồ.

- Xác định mức độ khó khăn, xác định độ chính xác khi thành lập bản đồ cho khu vực.

- Kết hợp các quy định, quy phạm trong thành lập bản đồ địa hình với các đặc điểm địa lý, kinh tế - xã hội của khu vực thành lập bản đồ.

- Chuẩn bị các thiết bị bay chụp, kiểm tra sự đồng bộ của hệ thống từ máy ảnh, GPS, $\mathrm{IMU}$, pin và phần mềm điều khiển. Trong thực nghiệm này chúng tôi đã sử dụng thiết bị Drone InSpire 1 với camera X3 có độ phân giải $12.4 \mathrm{M}$, có thể bay cao tối đa 500 $\mathrm{m}$ so với vị trí cất cánh, trên máy bay được tích hợp hệ thống cân bằng điện tử IMU,...

- Chuẩn bị các công việc phục vụ cho ca bay chụp:

+ Thu thập các tài liệu liên quan đến khu vực cần thành lập bản đồ.

+ Liên hệ với các cơ quan nhà nước, chính quyền địa phương làm thủ tục và xin giấy phép bay;

+ Số liệu tọa độ, độ cao các điểm khống chế các cấp;

+ Khảo sát khu đo, chọn vị trí cất hạ cánh;

+ Chuẩn bị và kiểm tra các thiết bị máy và phương tiện phục vụ công tác bay chụp ảnh. (Xem hình 1)

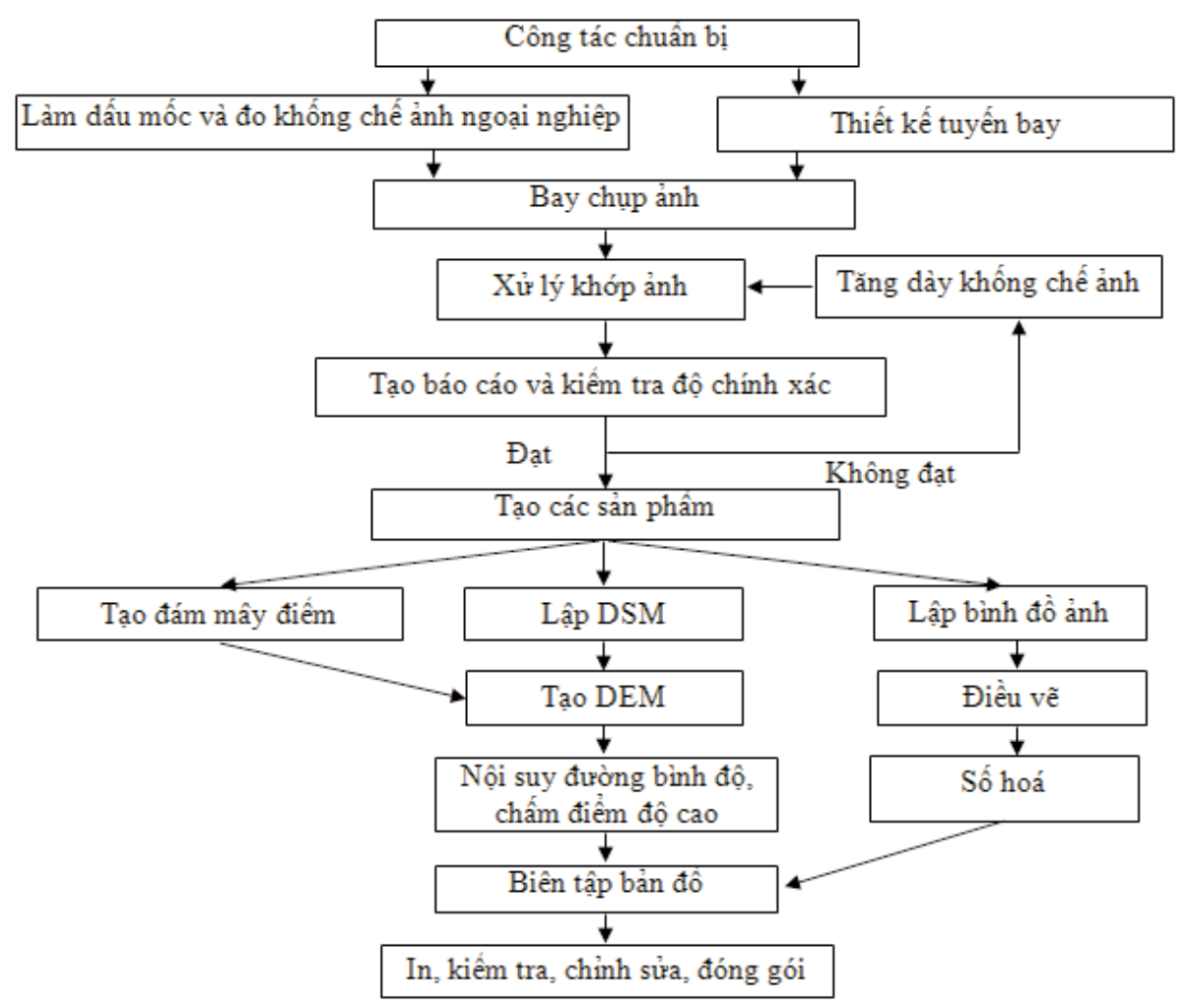

Hình 1: Sơ đồ quy trình thành lập bản đồ địa hình bằng ảnh máy bay không người lái 


\subsection{Thiết kế tuyến bay}

Công tác thiết kế bay được thực hiện bằng phần mềm Map pilot, các công việc gồm xác định phạm vi bay chụp, độ cao bay chụp, số đường bay, mật độ phủ trùm giữa các ảnh, ...

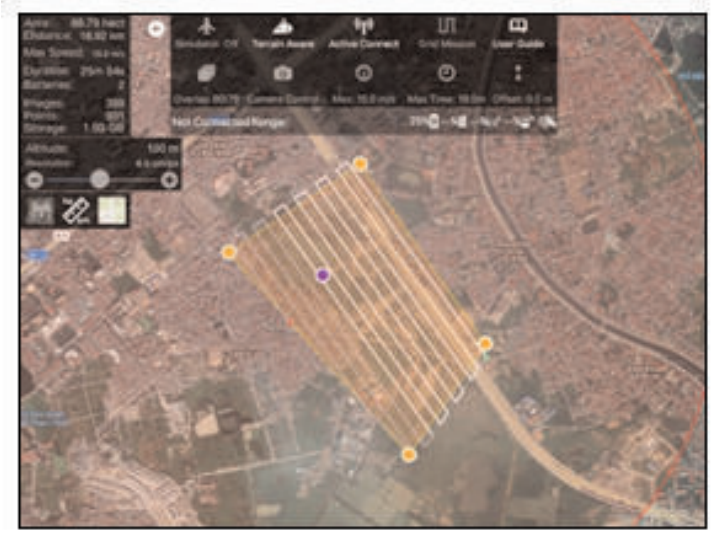

Hình 2: Tuyến bay được thiết kế cho khu bay chup

Quá trình thực nghiệm đã được tính toán và thiết kế độ cao bay chụp của thiết bị bay là $121 \mathrm{~m}$ so với vị trí đứng trạm điều khiển với độ phủ dọc:81\%; độ phủ ngang: $74 \%$; độ phân giải mặt đất (GSD): $6.5 \mathrm{~cm} /$ pixel; tổng số ảnh chụp: 388 ảnh;

\section{4. Đo khống chế ngoại nghiệp và làm dấu mốc}

Công tác đo đạc khống chế ảnh được thực hiện bằng thiết bị đo GPS của hãng
Trimbe loại máy R3 với 10 điểm khống chế trong đó có 8 điểm được sử dụng để tính toán và 2 điểm kiểm tra. Các điểm khống chế được sơn lên mặt đường (kích thước $40 \times 40 \mathrm{~cm}$ trong đó độ rộng của nét là $8 \mathrm{~cm}$ ) do đây là khu vực đô thị các điểm khống chế nằm ở ven đường là phù hợp nhất. (Xem hinh 3)

\subsection{Bay chup}

Sau khi thiết kế tuyến bay và đo khống chế ngoại nghiệp, ta cần tiến hành kiểm tra hệ thống UAV xem có đạt được các yêu cầu cho công tác bay chụp ảnh không, nếu đạt được những yêu cầu này thì ta mới tiến hành bay chụp. Trước khi bay chụp tại thực địa, cần phải tiến hành kiểm tra không gian bao quanh vị trí được lựa chọn phục vụ cho cất, hạ cánh an toàn, bao gồm: xác định khả năng thông thoáng để thu tín hiệu GPS được tốt nhất, ước lượng gần đúng chiều cao một số đối tượng cao nhất trong khu chụp (nhà cao tầng, cây, cột ăng ten, đường dây điện...). Sau khi thiết lập xong các tham số và kiểm tra điều kiện đảm bảo an toàn bay tiến hành công tác bay chụp thu nhận dữ liệu.

\subsection{Xử lý khớp ảnh}

Quá trình xử lý khớp ảnh được thực hiện trên phần mềm Pix4Dmapper. Trước khi tiến hành xử lý khớp ảnh trên phần mềm, tiến hành tạo thư mục lưu ảnh trong máy
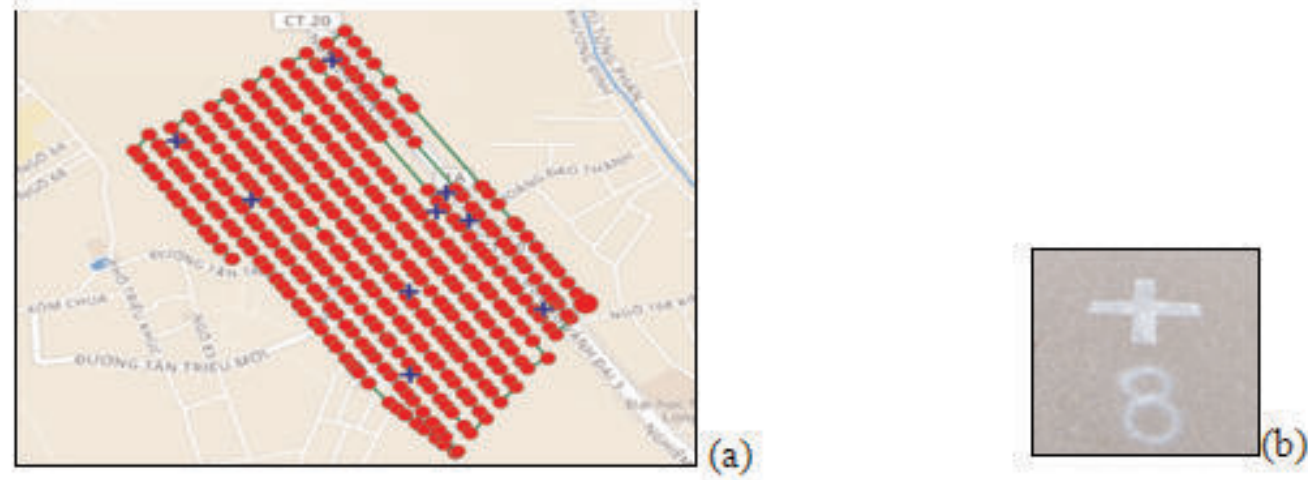

Hình 3: Bố trí các điểm khống chế ảnh (a) và điểm khống chế ảnh mặt đất (b) 
tính.

Để có hình ảnh chất lượng tốt, cần thiết phải xác định giá trị biến dạng do ống kính gây ra. Các tham số của máy ảnh sẽ được nhập vào trong phần khai báo về máy ảnh để phần mềm có thể khử sai số biến dạng ống kính trong quá trình xử lý ảnh.

Quá trình tiến hành xử lý khớp ảnh được thực hiện thông qua 6 bước:

+ Bước 1: Đưa các bức ảnh sau khi chụp vào phiên làm việc (Add Images). Những tấm ảnh này có toạ độ theo toạ độ của tuyến bay được thiết kế (thường là hệ toạ độ WGS-84);

+ Bước 2: Nhập các điểm khống chế ảnh ở cùng hệ toạ độ với hệ toạ độ của ảnh;

+ Bước 3: Tiến hành đánh dấu các điểm khống mặt đất trên các tấm ảnh. Ở bước này cần chú ý để tăng độ chính xác thì những điểm khống chế nào có trên ảnh thì cần phải đánh dấu hết:

+ Bước 4: Thiết lập các thông số cho các quá trình xử lý ảnh

+ Bước 5: Tiến hành xử lý khớp ảnh.

\subsection{Tăng dày khống chế ảnh}

Ngày nay với sự phát triển mới của phương pháp tam giác ảnh cho phép nâng cao độ chính xác và hiệu quả của công tác tăng dày. Việc tăng dày tam giác cho ảnh UAV được thực hiện qua các bước sau:

+ Đo các nối mô hình: quá trình này được thực hiện hoàn toàn tự động trong các phần mềm xử lý ảnh nội nghiệp;
+ Đo các điểm khống chế mặt đất: các điểm này được đo thủ công bằng cắt lập thể;

+ Bình sai khối tam giác ảnh hàng không: tính toán xác định tọa độ tâm ảnh và các điểm ảnh, sau đó hiệu chỉnh lặp bằng cách loại dần ra các điểm có sai số vượt hạn sai cho phép;

+ Độ chính xác của các điểm khống chế ảnh cần phải cao hơn độ chính xác của điểm địa vật trên bản đồ ít nhất một cấp.

+ Sai số cho phép của điểm khống chế tăng dày chỉ được phép bằng 2 lần sai số trung bình trong bảng 2 với số lần xuất hiện tối đa là $5 \%$. đối với điểm độ cao của điểm tăng dày vùng khó khăn cho phép số lần xuất hiện tối đa là $10 \%$. (Xem bảng 2)

\subsection{Tạo các sản phẩm sau xử lý ảnh}

\subsection{1. Đám mây điểm (Point Cloud)}

Các phần mềm xử lý hình ảnh dựa vào việc tìm kiếm tự động hàng ngàn các điểm chung giữa các ảnh có độ chồng phủ (overlap) cao. Mỗi điểm đặc trưng được tìm thấy trên mỗi ảnh được gọi là một Keypoint. Khi cùng một keypoint được tìm thấy trên hai ảnh là như nhau, chúng sẽ được kết hợp lại và mỗi nhóm keypoint phù hợp chính xác sẽ tạo thành một điểm 3D. Tập hợp của nhiều điểm 3D được tìm thấy sẽ tạo ra các đám mây điểm 3D (3D point cloud), và từ các đám mây điểm này phần mềm có thể tái dựng lại các đối tượng, lập bản đồ địa hình 3D, cũng như tạo ra nhiều các sản phẩm khác [5].

Khi có sự chồng phủ cao giữa 2 hình

Bảng 2: Sai số trung bình cho phép của toạ độ và độ cao điểm khống chế ảnh

\begin{tabular}{|c|c|c|c|c|c|c|}
\hline \multirow{2}{*}{} & \multirow{2}{*}{$\begin{array}{c}\text { Sai số trung bình mặt phẳng } \\
\text { (theo tỳ lệ bản đồ) }\end{array}$} & \multicolumn{5}{|c|}{$\begin{array}{c}\text { Sai số trung bình của độ cao }(\mathrm{m}) \\
\text { (theo khoảng cao đều của đường bình độ) }\end{array}$} \\
\cline { 3 - 7 } & & $0,5 \div 1$ & 2 & 2,5 & 5 & $>10$ \\
\hline Vùng đồng bằng & $\pm 0,35 \mathrm{~mm}$ & $1 / 5$ & $1 / 4$ & $1 / 4$ & & \\
\hline Vùng đồi & $\pm 0,35 \mathrm{~mm}$ & & & $1 / 4$ & $1 / 3$ & \\
\hline Vùng núi & $\pm 0,50 \mathrm{~mm}$ & & & & $1 / 3$ & $1 / 3$ \\
\hline
\end{tabular}


ảnh, những khu vực chung sẽ lớn hơn và số các điểm keypoint tìm được sẽ nhiều hơn, chúng có thể kết hợp cùng nhau và khi số lượng điểm keypoint càng nhiều, sẽ có càng nhiều hơn các điểm 3D chính xác được xử lý tính toán. Vì vậy, quy tắc chính khi chụp ảnh UAV là phải duy trì độ chồng phủ cao giữa các hình ảnh chụp trên cùng hướng bay và giữa các đường bay.

Các điểm trong đám mây điểm này có các giá trị về toạ độ, độ cao và giá trị về màu sắc. Điều này giúp chúng ta có thể dễ dàng chấm các điểm mặt đất để nội suy mô hình số độ cao DEM.

3.8.2. Mô hình số bề mặt $D S M$ và Mô hình số độ cao DEM

Mô hình số bề mặt là một sản phẩm được phần mềm Pix4Dmapper sinh ra tự động trong quá trình xử lý ảnh (hình $4 a)$. Ta có thể kết hợp mô hình số bề mặt và đám mây điểm để nội suy ra mô hình số độ cao DEM, đường bình độ và điểm độ cao mặt đất.

Sau khi có đám mây điểm và mô hình số bề mặt, ta mở chúng trên phần mềm Global Mapper để tạo DEM (hình 4b). (Xem hình 4)

\subsubsection{Bình đồ ảnh}

Bình đồ ảnh cũng là một sản phẩm được sinh ra sau quá trình xử lý ảnh và đượcdùng để số hoá các yếu tố nội dung trên ảnh phục vụ công tác biên tập thành lập bản đồ.

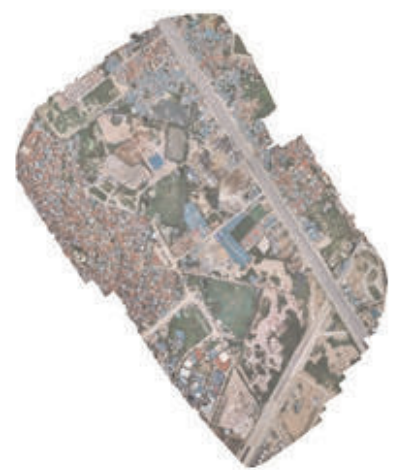

Hình 5: Bình đồ ảnh của khu bay chụp

\subsection{Nội suy đường bình độ và chấm điểm độ cao}

Sau khi có đám mây điểm và DSM, ta mở chúng trên phần mềm Global Mapper để nội suy đường bình độ và các điểm độ cao. Lưu ý khi chấm các điểm lên đám mây điểm thì ta chấm vào các điểm dưới mặt đất, không chấm lên các điểm địa vật, hay cây cối cao vì nó sẽ nhận độ cao của các điểm đó làm độ cao địa hình, như vậy sẽ làm DEM sai, dẫn đến đường bình độ nội suy ra cũng sẽ sai.

Nội suy được đường bình độ và các điểm độ cao xong, ta sẽ xuất các lớp này theo định dạng *.dxf để sau đó ta mở trên phần mềm MicroStation biên tập, trình bày bản đồ.

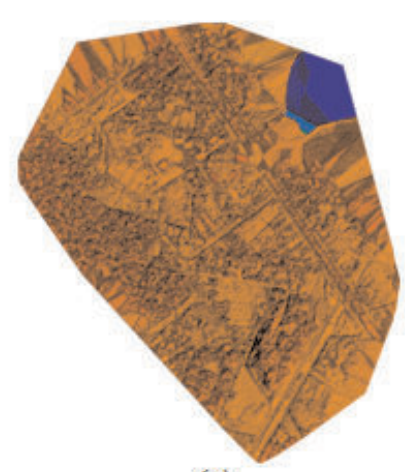

(a)

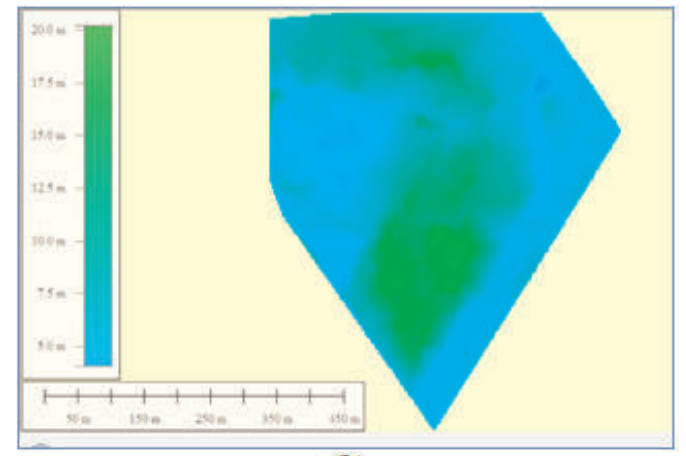

(b)

Hình 4: Mô hình số bề mặt DSM và Mô hình số độ cao DEM của khu vực thực nghiệm 


\subsection{Số hoá các đối tượng trên ảnh}

Đối với quá trình thực nghiệm thành lập bản đồ địa hình tỷ lệ 1:1.000 khu vực xã Tân Triều, huyện Thanh Trì, nghiên cứu thực hiện cắt một phần của bình đồ ảnh cho số hoá, biên tập bản đồ để giảm nhẹ khối lượng công việc. Mảnh ảnh này tương ứng với mảnh bản đồ tỷ lệ 1:1.000 có phiên hiệu F-48-80-(9-f-III).

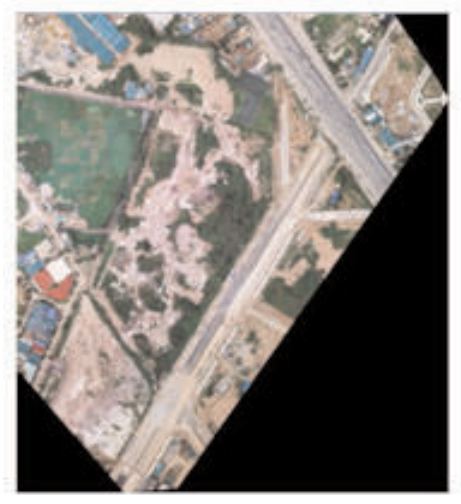

Hình 6: Mảnh ảnh để số hoá bản đồ khu vực thực nghiệm

Các đối tượng có trên ảnh được số hoá dựa theo [6]:

- Thủy hệ và các yếu tố liên quan: Trên bình đồ ảnh, tiến hành đo vẽ toàn bộ hệ thống thủy hệ: các đường mép nước của các hệ thống sông, suối, ao, hồ được vẽ theo thời điểm chụp ảnh; Giải đoán triệt để các thiết bị phụ thuộc và tính chất của chúng như; hệ thống cống tưới tiêu, máng dẫn nước, kênh mương xây và đào đắp và các ao, hồ, đập, đê.

- Giao thông và các yếu tố liên quan: Đo vẽ toàn bộ hệ thống giao thông trên mô hình lập thể từ cấp đường mòn trở lên. Với những đường có độ rộng $\geq 0,5 \mathrm{~mm}$ trên bản đồ thì thể hiện 2 nét theo độ rộng thực tế của đối tượng đường. Các loại đường giao thông được phân biệt thành 2 loại: nửa tỷ lệ vẽ 1 nét vào tim đường, theo tỷ lệ vẽ 2 nét vào 2 bên mép đường.
- Dân cư và các yếu tố liên quan: Đo vẽ tất cả các loại nhà; Các nhà, khu nhà có diện tích $\geq 5 \mathrm{~mm}^{2}$ trên bản đồ thì vẽ dạng diện và vẽ theo móng nhà. Các nhà, khu nhà có diện tích $<5 \mathrm{~mm}^{2}$ trên bản đồ thì được biểu thị bằng chấm vào giữa nhà đó; Các khu để vật tư, bãi rác thì đc vẽ theo viền của chúng.

Tương tự như vậy với các lớp thực vật, thổ nhưỡng; các đối tượng lớp ranh giới được chuyển vẽ từ các bản đồ $364, \ldots$

\subsection{Biên tập bản đồ}

Sau khi số hoá các yếu tố nội dung trên bản đồ, ta biên tập các yếu tố nội dung này theo phụ lục 4 của quy phạm của thành lập bản đồ địa hình tỷ lệ 1:500 $1: 1.000$. Việc biên tập bao gồm gán thuộc tính đồ họa cho các yếu tố, chuẩn hóa các đối tượng về màu sắc, đường nét, kích thước chữ, danh pháp; Biên tập ký hiệu cho các đối tượng dạng đường và dạng điểm; Biên tập về màu sắc cho viền, nền và trải kí hiệu (cell) cho các đối tượng dạng vùng (thường là vùng thực vật); Biên tập chữ chú thích cho các đối tượng; Trình bày chú giải ngoài khung.

\section{Kết quả thực nghiệm}

\section{(Xem hinh 7)}

\section{Kết luận}

Sử dụng ảnh máy bay không người lái trong thành lập bản đồ địa hình là bước đột phá trong ngành khoa học bản đồ, cho phép đẩy nhanh tốc độ thành lập bản đồ với độ chính xác cao mà giá thành lại thấp.

Việc sử dụng tư liệu ảnh chụp từ thiết bị bay không người lái là một phương pháp khắc phục những nhược điểm của phương pháp chụp ảnh bằng máy bay chuyên dụng đối với những khu vực có diện tích nhỏ và đo vẽ bản đồ tỷ lệ lớn.

Tư liệu ảnh chụp từ thiết bị bay không người lái do được chụp từ khoảng cách gần nên mức độ chi tiết các yếu tố địa vật rất 


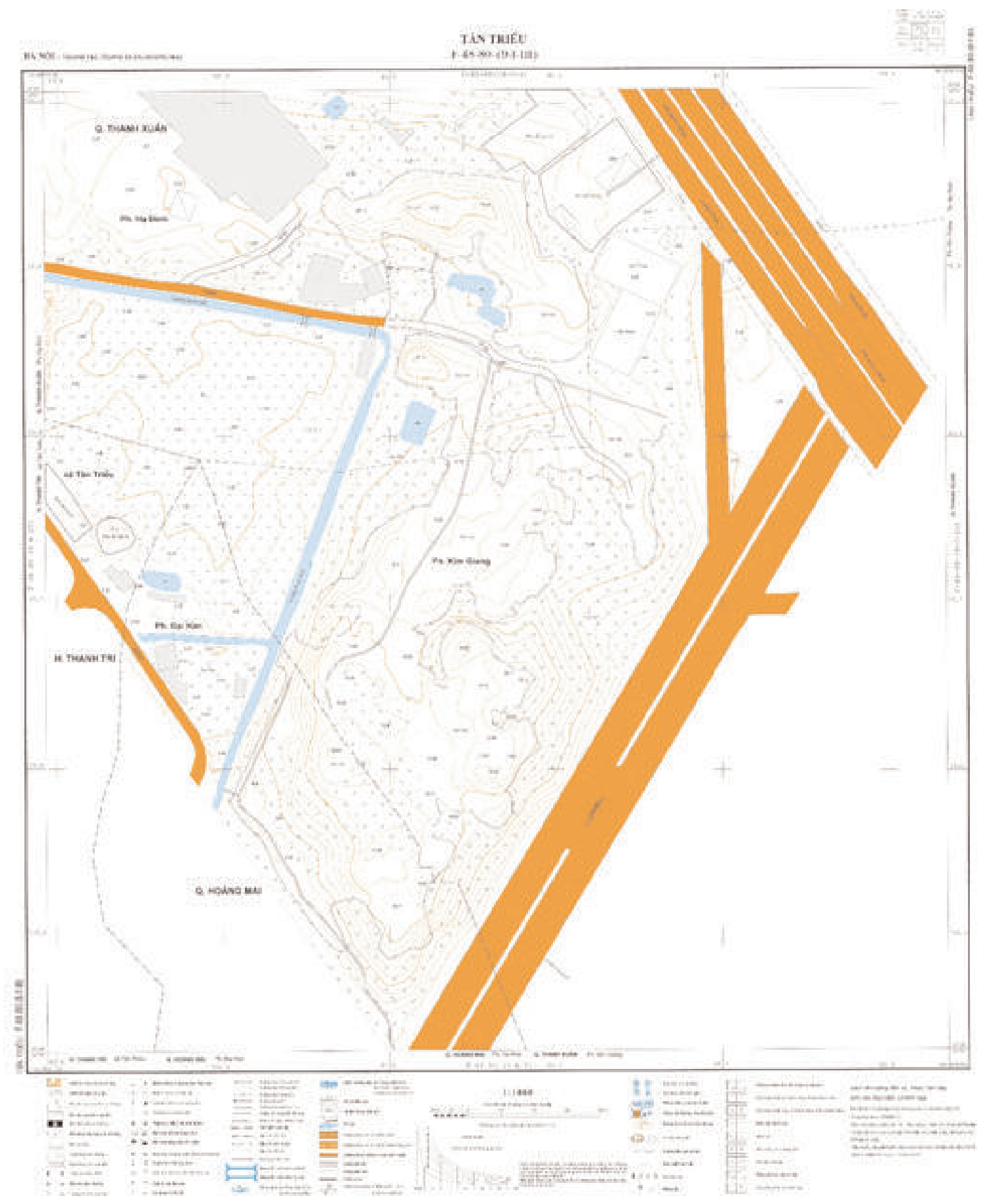

Hình 7: Mảnh bản đồ địa hình tỷ lệ 1:1000 F-48-80-(9-f-III) 
cao, thuận tiện cho công tác giải đoán và điều vẽ ảnh. Sản phẩm không những đáp ứng các yêu cầu kỹ thuật trong thành lập bản đồ địa hình mà đáp ứng tốt việc thành lập bản đồ 3D, phục cho các lĩnh vực nhu: nghiên cứu lập quy hoạch cho các khu đô thị, khảo sát các tuyến giao thông, tuyến đường dây ...

Với những nhiệm vụ có tính cấp bách, thời tiết không thuận lợi cho công tác bay chụp ảnh bằng thiết bị chuyên dụng. Việc sử dụng phương pháp này có ưu điểm khắc phục được thời tiết do tầm bay thấp.

Tuy nhiên, để ứng dụng ảnh chụp từ thiết bị bay không người lái vào việc thành lập bản đồ địa hình, trước mắt cần phải thực hiện các công việc cụ thể sau:

Về nhân lực, cần phải đào đào tạo các chuyên gia có khả năng tiếp nhận và điều khiển thành thạo thiết bị máy bay không người lái, xử lý ảnh chụp nội nghiệp.

Cần có sự phối hợp chặt chẽ, tạo sự thuận lợi trong việc nghiên cứu áp dụng khoa học công nghệ giữa các bên có liên quan: quản lý máy bay và thực hiện bay, quản lý cấp phép bay và đơn vị áp dụng công nghệ để có thể hoàn thiện và đưa vào sử dụng phổ biến công nghệ này ở nước ta trong thời gian sớm nhất. $\bigcirc$

\section{Tài liệu tham khảo}

[1]. Trương Anh Kiệt (2001), Giáo trình Cơ sở đo ảnh, NXB Giao thông Vận tải. Hà Nội, 2001.
[2]. Phạm Vọng Thành (2000), Giáo trình Cơ sở chụp ảnh và chụp ảnh hàng không, NXB Giao thông Vận tải. Hà Nội, 2000.

[3]. Turner, D., A. Lucieer, and C. Watson, An automated technique for generating georectified mosaics from ultra-high resolution unmanned aerial vehicle (UAV) imagery, based on structure from motion (SfM) point clouds. Remote Sensing, 2012.4(5): p. 1392-1410.

[4]. Morgan, D. and E. Falkner, Aerial mapping: methods and applications. 2001: CRC Press.

[5]. http://www.geoviet.vn/goc-kythuat/vn/400/464/533/2017/xu-ly-du-lieuanh-uav-voi-phan-mem-pix4dmapper2.0.x.aspx

[6]. Bộ Tài nguyên và Môi trường, 2005, Thông tư số 68/2015/TT-BTNMT ngày 22/12/2015 của Bộ Tài nguyên và Môi trường Quy định kỹ thuật đo đạc trực tiếp địa hình phục vụ thành lập bản đồ địa hình và cơ sở dữ liệu nền địa lý tỷ lệ $1: 500$, 1:1000, 1:2000, 1:5000.

[7]. Bùi Tiến Diệu, Nguyễn Cẩm Vân, Hoàng Mạnh Hùng, Đồng Bích Phương, Nhữ Việt Hà, Trần Trung Anh, Nguyễn Quang Minh (2016), "Xây dựng mô hình số bề mặt và bản đồ trực ảnh sử dụng công nghệ đo ảnh máy bay không người lái (UAV)", Hội nghị Khoa học: Đo đạc Bản đồ với ứng phó biến đổi khí hậu. $\bigcirc$

\section{Summary}

\section{Uses image data from unmanned aerial vehicles (UAV) in the establishment of large-scale terrain map}

\section{Mai Van Sy, Bui Ngoc Quy, Pham Van Hiep, Le Dinh Quy}

Unmanned Aerial Vehicles (UAV) technology has been interested in many fields, including the establishment of topographic maps. This paper presents the results of the study using UAV image data for establishment of topographic map F-48-80- (9-f-III) in Tan Trieu, Thanh Tri, Ha Noi. O 